\title{
SYNTHESIS AND CRYSTAL STRUCTURES OF DIOXOMOLYBDENUM(VI) COMPLEXES DERIVED FROM SIMILAR BENZOHYDRAZONE DERIVATIVES WITH CATALYTIC PROPERTY
}

\author{
GUO-PING CHENG, LING-WEI XUE*, WEI-CHUN YANG, GAN-QING ZHAO
}

College of Chemistry and Chemical Engineering, Pingdingshan University, Pingdingshan Henan 467000, P.R. China

(Received: July 18, 2012 - Accepted: November 20, 2012)

\begin{abstract}
A pair of new dioxomolybdenum(VI) complexes, $\left[\mathrm{MoO}_{2} \mathrm{~L}^{1}(\mathrm{MeOH})\right] \cdot\left[\mathrm{MoO}_{2} \mathrm{~L}^{1}(\mathrm{EtOH})\right](\mathbf{1})$ and $\left[\mathrm{MoO}_{2} \mathrm{~L}^{2}(\mathrm{MeOH})\right] \cdot\left[\mathrm{MoO} \mathrm{L}^{2}\left(\mathrm{EtOH}^{2}\right)\right](\mathbf{2})$, where $\mathrm{L}^{1}$ and L $\mathrm{L}^{2}$ are the dianionic forms of $N^{\prime}$-(2-hydroxy-3-methoxybenzylidene)-2-hydroxy-3-methylbenzohydrazide and $N^{\prime}$-(3-ethoxy-2-hydroxybenzylidene)-2-hydroxy-3methylbenzohydrazide, respectively, have been synthesized and characterized by elemental analysis, FT-IR spectra, and single crystal X-ray determination. The crystal of (1) is triclinic: space group $P-1, a=8.106(2), b=13.412(3), c=18.045(3) \AA, \alpha=83.634(2), \beta=84.809(2), \gamma=87.746(2)^{\circ}, V=1941.0(7) \AA^{3}, Z=2, R_{1}$ $=0.0382, w R_{2}=0.0919$. The crystal of (2) is triclinic: space group $P-1, a=7.350(2), b=11.292(3), c=24.914(3) \AA, \alpha=85.213(2), \beta=82.411(2), \gamma=71.012(2)^{\circ}$, $V=1936.1(7) \AA^{3}, Z=2, R_{1}=0.0425, w R_{2}=0.0877$. The Mo atoms in the complexes are coordinated by one phenolate $\mathrm{O}$, one imine $\mathrm{N}$ and one enolic $\mathrm{O}$ atoms of the benzohydrazone ligand, two oxo $\mathrm{O}$ atoms, and one solvate $\mathrm{O}$ atom, forming octahedral coordination. In the crystal structures, adjacent two complex molecules are linked by methanol and ethanol ligands through intermolecular $\mathrm{O}-\mathrm{H} \cdots \mathrm{O}$ hydrogen bonds, forming dimers. The catalytic property of sulfoxidation for the complexes was studied.
\end{abstract}

Keywords: Dioxomolybdenum; benzohydrazone; crystal structure; hydrogen bonds; catalytic property.

\section{INTRODUCTION}

The coordination chemistry of dioxomolybdenum complexes with multidentate ligands has received considerable attention in recent years for their catalytic properties ${ }^{1-4}$ and versatile structures. ${ }^{5-7}$ Benzohydrazone derivatives are a kind of special Schiff bases which have been used as interesting ligands in coordination chemistry. ${ }^{8-10}$ To date, hundreds of complexes of copper, iron, vanadium, manganese, molybdenum, etc. derived from benzohydrazone derivatives have been reported. However, due to the best of our knowledge, dioxomolybdenum complexes with such ligands have seldom been reported so far. Some of these dioxomolybdenum complexes have been shown to possess oxygen atom transfer properties as they were found to oxidize thiols, hydrazine, polyketones, and tertiary phosphines. ${ }^{11-13}$ As an extension of the work on the structures and catalytic properties of such complexes, we report in this paper the synthesis, structures, and properties of a pair of new dioxomolybdenum $(\mathrm{VI})$ complexes, $\left[\mathrm{MoO}_{2} \mathrm{~L}^{1}(\mathrm{MeOH})\right] \cdot\left[\mathrm{MoO}_{2} \mathrm{~L}^{1}(\mathrm{EtOH})\right]$ (1) and $\left[\mathrm{MoO}_{2} \mathrm{~L}^{2}(\mathrm{MeOH})\right] \cdot\left[\mathrm{MoO}_{2} \mathrm{~L}^{2}(\mathrm{EtOH})\right]$ (2), where $\mathrm{L}^{1}$ and $\mathrm{L}^{2}$ are the dianionic forms of $N^{\prime}$-(2-hydroxy-3-methoxybenzylidene)-2-hydroxy-3methylbenzohydrazide $\left(\mathrm{H}_{2} \mathrm{~L}^{1}\right)$ and $N^{\prime}$-(3-ethoxy-2-hydroxybenzylidene)-2hydroxy-3-methylbenzohydrazide $\left(\mathrm{H}_{2} \mathrm{~L}^{2}\right)$, respectively (Scheme 1).<smiles>COc1cccc(/C=N/NC(=O)c2cccc(C)c2O)c1O</smiles>

$\mathrm{H}_{2} \mathbf{L}^{1}$<smiles>CCOc1cccc(/C=N/NC(=O)c2cccc(C)c2O)c1O</smiles>

$\mathrm{H}_{2} \mathrm{~L}^{2}$
Scheme 1: The benzohydrazone ligands

\section{EXPERIMENTAL}

Materials and Methods: 3-Methoxysalicylaldehyde, 3-ethoxysalicylaldehyde, and 2-hydroxy-3-methylbenzohydrazide were purchased from Fluka. Other reagents and solvents were analytical grade and used without further purification. Elemental $(\mathrm{C}, \mathrm{H}$, and $\mathrm{N})$ analyses were made on a Perkin-Elmer Model 240B automatic analyzer. IR spectra were recorded on an IR-408 Shimadzu 568 spectrophotometer. ${ }^{1} \mathrm{H}$ NMR spectra were recorded on Bruker Avance $300 \mathrm{MHz}$ spectrometer.

Syntheses of $H_{2} L^{1}$ and $H_{2} L^{2}$ : The two compounds were prepared by same method. Salicylaldehyde derivatives $(0.01 \mathrm{~mol})$ and 2-hydroxy-3methylbenzohydrazide $(1.66 \mathrm{~g}, 0.01 \mathrm{~mol})$ were mixed in methanol $(30 \mathrm{~mL})$. The mixture was stirred at reflux for $30 \mathrm{~min}$ and three quarter of the solvent was evaporated, to give colorless solid product of the benzohydrazone ligand, which was collected by filtration and dried in vacuum containing anhydrous
$\mathrm{CaCl}_{2}$. For $\mathrm{H}_{2} \mathrm{~L}^{1}$ : Yield $2.7 \mathrm{~g}(90 \%)$. Analysis: Calcd. (\%) for $\mathrm{C}_{16} \mathrm{H}_{16} \mathrm{~N}_{2} \mathrm{O}_{4}: \mathrm{C}$ 64.0, H 5.4, N 9.3. Found (\%): C 63.9, H 5.3, N 9.4. For $\mathrm{H}_{2} \mathrm{~L}^{2}:$ : Yield $2.9 \mathrm{~g}$ (92\%). Analysis: Calcd. (\%) for $\mathrm{C}_{17} \mathrm{H}_{18} \mathrm{~N}_{2} \mathrm{O}_{4}: \mathrm{C} 65.0, \mathrm{H} 5.8, \mathrm{~N} 8.9$. Found (\%): C 64.8, H $5.7, \mathrm{~N} 9.0$.

Synthesis of the complexes: $\mathrm{MoO}_{2}(\mathrm{acac})_{2}(0.1 \mathrm{mmol}, 33 \mathrm{mg})$ in ethanol $(10 \mathrm{~mL})$ was added with stirring to the corresponding benzohydrazone ligand $(0.1 \mathrm{mmol})$ in methanol $(10 \mathrm{~mL})$. The mixture was stirred at refluxed for 30 min to give an orange solution. The solution was left still at room temperature in air to give orange block-shaped single crystals, which were collected by filtration and dried in vacuum containing anhydrous $\mathrm{CaCl}_{2}$. For complex (1): Yield $32 \mathrm{mg}(69 \%)$. Analysis: Calcd. (\%) for $\mathrm{C}_{35} \mathrm{H}_{38} \mathrm{Mo}_{2} \mathrm{~N}_{4} \mathrm{O}_{14}$ : C 45.2, H 4.1, $\mathrm{N}$ 6.0. Found (\%): C 45.0, H 4.2, N 6.1. For complex (2): Yield $23 \mathrm{mg}(48 \%)$. Analysis: Calcd. (\%) for $\mathrm{C}_{37} \mathrm{H}_{42} \mathrm{Mo}_{2} \mathrm{~N}_{4} \mathrm{O}_{14}: \mathrm{C} 46.4, \mathrm{H} 4.4, \mathrm{~N}$ 5.8. Found (\%): $\mathrm{C}$ 46.3, H 4.4, N 5.9.

X-ray Crystal Determination: Data were collected from selected crystals mounted on glass fibers. The data for the complexes were processed with SAINT [14] and corrected for absorption using SADABS. ${ }^{15}$ Multi-scan absorption corrections were applied with $\psi$ scans. ${ }^{16}$ The structures were solved by direct method using the SHELXS-97 program and refined by full-matrix least-squares techniques on $F^{2}$ using anisotropic displacement parameters. ${ }^{17}$ All non-hydrogen atoms were refined anisotropically. The methanol and ethanol hydrogen atoms were located from difference Fourier maps and refined isotropically, with $\mathrm{O}-\mathrm{H}$ distances restrained to $0.85(1) \AA$. The remaining hydrogen atoms were placed at the calculated positions. The crystallographic data for the complexes are listed in Table 1. Selected bond lengths and angles are given in Table 2 .

Catalytic Oxidation: The dioxomolybdenum complexes $(0.001 \mathrm{M})$ and phenyl methyl sulfide $(0.1 \mathrm{M})$ were dissolved at room temperature in a mixture of $\mathrm{CH}_{2} \mathrm{Cl}_{2}$ and $\mathrm{CH}_{3} \mathrm{OH}(6: 4)$ together with 1,3,5-trimethoxybenzene $(0.1 \mathrm{M})$ as internal standard. The resulting solution was cooled to $283 \mathrm{~K}$ and $\mathrm{H}_{2} \mathrm{O}_{2}$ $(35 \% \mathrm{w} / \mathrm{w})$ added dropwise $(0.125 \mathrm{M})$. An aliquot of the reaction solution $(2.0 \mathrm{~mL})$ was quenched with $5 \mathrm{~mL}$ of a stock solution of $\mathrm{Na}_{2} \mathrm{SO}_{3}(0.1 \mathrm{M})$ and extracted with dichlormethan (three times $4 \mathrm{~mL}$ ). From the collected organic phases the solvent was removed under reduced pressure to complete dryness and the residue redissolved in deuterated chloroform $(0.6 \mathrm{~mL})$ and analyzed by ${ }^{1} \mathrm{H}$ NMR to determine the yield with reference to the internal standard 1,3,5-trimethoxybenzene.

\section{RESULTS AND DISCUSSION}

The reaction of the benzohydrazone ligands with $\mathrm{MoO}_{2}(\mathrm{acac})_{2}$ in the mixture solvent of ethanol and methanol $(\mathrm{V}: \mathrm{V}=1: 1)$ affords the orange products of complexes (1) and (2) (Scheme 2). The complexes are soluble in DMF, DMSO, methanol, ethanol, and acetonitrile. We have attempted to grow diffraction quality crystals from various solvents; however, well-shaped single crystals suitable for X-ray diffraction were finally obtained from the mixture solvent of ethanol and methanol containing the complexes. 
Table 1 Crystal and structure refinement data for the complexes

\begin{tabular}{|c|c|c|}
\hline & (1) & (2) \\
\hline Molecular formula & $\mathrm{C}_{35} \mathrm{H}_{38} \mathrm{Mo}_{2} \mathrm{~N}_{4} \mathrm{O}_{14}$ & $\mathrm{C}_{37} \mathrm{H}_{42} \mathrm{Mo}_{2} \mathrm{~N}_{4} \mathrm{O}_{14}$ \\
\hline Molecular weight & 930.6 & 958.6 \\
\hline Crystal system & Triclinic & Triclinic \\
\hline Space group & $P-1$ & $P-1$ \\
\hline$a / \AA ̊$ & $8.106(2)$ & $7.350(2)$ \\
\hline$b / \AA ̊$ & $13.412(3)$ & $11.292(3)$ \\
\hline$c / \AA ̊$ & $18.045(3)$ & 24.914(3) \\
\hline$\alpha /{ }^{\circ}$ & $83.634(2)$ & $85.213(2)$ \\
\hline$\beta /{ }^{\circ}$ & $84.809(2)$ & $82.411(2)$ \\
\hline$\gamma /{ }^{\circ}$ & $87.746(2)$ & $71.012(2)$ \\
\hline$V / \AA^{3}$ & 1941.0(7) & 1936.1(7) \\
\hline$Z$ & 2 & 2 \\
\hline$D_{\text {calc }}\left(\mathrm{g} \mathrm{cm}^{-3}\right)$ & 1.592 & 1.644 \\
\hline Crystal dimensions (mm) & $0.20 \times 0.20 \times 0.18$ & $0.20 \times 0.20 \times 0.17$ \\
\hline$\mu\left(\mathrm{mm}^{-1}\right)$ & 0.717 & 0.722 \\
\hline Radiation $\lambda$ & Mo K $\alpha(0.71073 \AA \dot{)})$ & Mo K $\alpha(0.71073 \AA ̊)$ \\
\hline$T_{\min } / T_{\max }$ & $0.8699 / 0.8818$ & $0.8691 / 0.8872$ \\
\hline Reflections measured & 14076 & 13006 \\
\hline Range/indices $(h, k, l)$ & $-10,9 ;-17,17 ;-23,16$ & $-9,9 ;-14,14 ;-31,22$ \\
\hline$\theta \operatorname{limit}\left({ }^{\circ}\right)$ & $2.52-27.00$ & $2.11-27.00$ \\
\hline Unique reflections & $8171\left[R_{\mathrm{int}}=0.0211\right]$ & $8162\left[R_{\mathrm{int}}=0.0221\right]$ \\
\hline Observed reflections $(I>2 \sigma(I))$ & 5914 & 6283 \\
\hline Parameters & 510 & 528 \\
\hline Restraints & 3 & 3 \\
\hline Goodness of fit on $F^{2}$ & 1.103 & 1.040 \\
\hline$R_{1}, w R_{2}\left[I^{3} 2 s(I)\right]^{\mathrm{a}}$ & $0.0382,0.0919$ & $0.0425,0.0877$ \\
\hline$R_{1}, w R_{2}(\text { all data })^{\mathrm{a}}$ & $0.0647,0.1113$ & $0.0606,0.0952$ \\
\hline
\end{tabular}

${ }^{\mathrm{a}} R_{1}=\mathrm{a}|| F_{o}|-| F_{c}|| / \mathrm{a}\left|F_{o}\right|, w R_{2}=\left[\AA a ̊ w\left(F_{o}^{2}-F_{c}^{2}\right)^{2} / \mathrm{a} w\left(F_{o}^{2}\right)^{2}\right]^{1 / 2}$

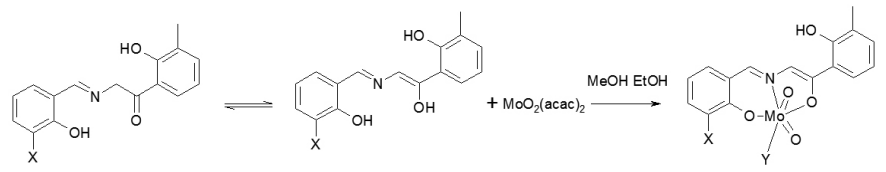

Scheme 2: The preparation of the complexes. $\mathrm{X}=\mathrm{OMe}$ for (1) and OEt for (2); $\mathrm{Y}=\mathrm{MeOH}$ and $\mathrm{EtOH}$.

Crystal Structure Description of the Complexes: The molecular structures of the complexes are shown in Figs. 1 and 2. The asymmetric unit of each complex contains two mononuclear dioxomolybdenum(VI) molecules, one with a methanol ligand and the other one with an ethanol ligand. The coordination geometry around Mo atom in each of the complexes is distorted octahedral.
The benzohydrazone ligand coordinates through the phenolate $\mathrm{O}$, imine $\mathrm{N}$, and enolic $\mathrm{O}$ atoms to the $\mathrm{MoO}_{2}$ moiety, forming a five- and a six-membered chelate rings with Mo atom. The sixth coordination is weakly coordinated by a solvate $\mathrm{O}$ atom. For the Mo1 coordination of complex (1), atoms O1, O3, N1, and $\mathrm{O} 5$ located at the equatorial plane show a high degree of planarity, with mean deviation from the plane of 0.023(3) $\AA$. The Mol atom deviates from the least-squares plane defined by the four equatorial donor atoms by $0.317(2)$ $\AA$ in the direction of the axial atom O6. For the Mo2 coordination of complex (1), atoms $\mathrm{O} 7, \mathrm{O} 10, \mathrm{~N} 3$, and $\mathrm{O} 13$ located at the equatorial plane show a high degree of planarity, with mean deviation from the plane of $0.037(3) \AA$. The Mo2 atom deviates from the least-squares plane defined by the four equatorial donor atoms by $0.326(2) \AA$ in the direction of the axial atom O11. For the Mo1 coordination of complex (2), atoms O1, O3, O5, and N1 located at the equatorial plane show a high degree of planarity, with mean deviation from the plane of $0.025(3) \AA$. The Mo1 atom deviates from the least-squares plane 
defined by the four equatorial donor atoms by $0.338(2) \AA$ in the direction of the axial atom O6. For the Mo2 coordination of complex (2), atoms $\mathrm{O} 8, \mathrm{O} 10, \mathrm{O} 12$, and $\mathrm{N} 3$ located at the equatorial plane show a high degree of planarity, with mean deviation from the plane of 0.003(3) $\AA$. The Mo2 atom deviates from the least-squares plane defined by the four equatorial donor atoms by $0.322(2)$ $\AA$ in the direction of the axial atom O13. The Mo-O bonds in each of the complexes are almost equal. The remaining coordinate bond lengths in both complexes are similar to each other, and also comparable to those observed in dioxomolybdenum(VI) complexes with benzohydrazone ligands. ${ }^{18,19}$ The angular distortion in the octahedral coordination comes from the bites O3Mo1-N1 and O10-Mo2-N3 taken by the benzohydrazone ligands. The dihedral angles between the benzene rings are $13.3(4)^{\circ}$ and $3.7(4)^{\circ}$ in complex (1), and $4.0(4)^{\circ}$ and $0.8(4)^{\circ}$ in complex (2). In the crystal of the complexes, adjacent two $\left[\mathrm{MoO}_{2} \mathrm{~L}\right]$ moieties are linked by two solvate ligands, viz. methanol and ethanol, through intermolecular $\mathrm{O}-\mathrm{H} \cdots \mathrm{O}$ hydrogen bonds, to form dimers (Fig. 3 for (1) and Fig. 4 for (2)).

Infrared Spectra: In the infrared spectra of the free benzohydrazone ligands, there showed stretching bands attributed to $\mathrm{C}=\mathrm{O}, \mathrm{C}=\mathrm{N}, \mathrm{C}-\mathrm{OH}$ and $\mathrm{NH}$ at about 1662,1636, 1182 and $3255 \mathrm{~cm}^{-1}$, respectively. In addition, strong bands indicative of the $-\mathrm{C}=\mathrm{N}-\mathrm{N}=\mathrm{C}-$ groups are observed at about $1623 \mathrm{~cm}^{-1}$. In the spectra of the complexes, there showed two prominent bands at about 943 and $906 \mathrm{~cm}^{-1}$, which attributed to cis-dioxomolybdenum groups. The bands due to $v_{\mathrm{C}=\mathrm{O}}$ and $v_{\mathrm{NH}}$ are absent in the complexes, and the formation of new C-O absorption at about $1257 \mathrm{~cm}^{-1}$. This suggests occurrence of ketoimine tautomerization of the ligands during complexation. ${ }^{18}$ The $-\mathrm{C}=\mathrm{N}-\mathrm{N}=\mathrm{C}-$ absorptions observed in the free ligands are shifted to lower wave numbers in the complexes, $1617 \mathrm{~cm}^{-1}$ for (1) and $1616 \mathrm{~cm}^{-1}$ for (2). The weak and broad bands centered at $3412 \mathrm{~cm}^{-1}$ for (1) and $3417 \mathrm{~cm}^{-1}$ for (2) were attributed to the $\mathrm{O}-\mathrm{H}$ vibrations. The weak bands in the low wave numbers are assigned to the Mo-O and Mo-N vibrations. The similar absorptions in the spectra indicate similar structures of the complexes.

Catalytic Sulfoxidation: The catalytic oxidation test of the complexes on the oxidation of sulfides under homogeneous conditions in solution using methyl phenyl sulfide (thioanisol) as substrate was shown as Scheme 3. As oxidant hydrogen peroxide was used in a slight excess of 1.25 equivalents based on the sulfide substrate. Reactions were run with $1 \mathrm{~mol} \%$ of catalyst based on the substrate at a temperature of $10{ }^{\circ} \mathrm{C}$. NMR technique has been used to monitor the formation of the sulfoxides with 1,3,5-trimethoxybenzene (TMB) as internal standard to determine the yields. The reaction was started by the addition of hydrogen peroxide. A control reaction under the same condition without any complex present leads to less than $1 \%$ sulfide conversion within 4 h. In the presence of the complexes conversions of about $77 \%$ for (1) and $79 \%$ for (2) of sulfide to the corresponding sulfoxide within 60 min reaction time were observed. After about $2 \mathrm{~h}$ in all cases the conversions of total amount of sulfide were complete. Under the given conditions no over oxidation to the sulfone could be detected. Both complexes show catalytic properties for the sulfoxidation.

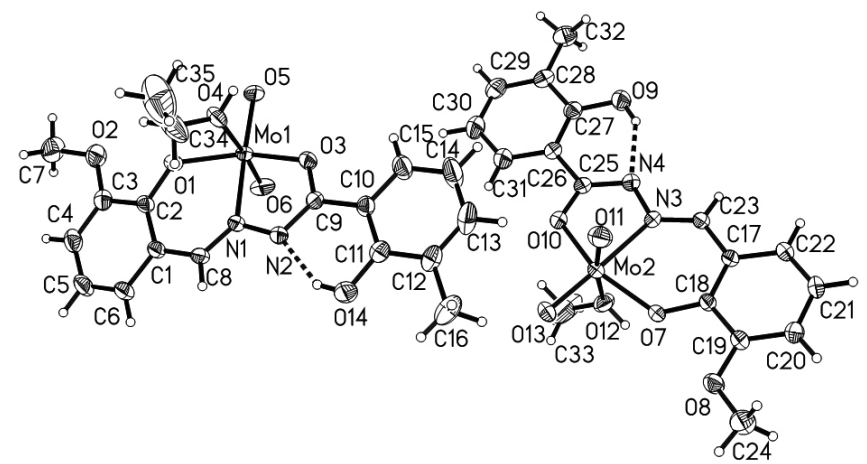

Figure 1 Molecular structure of (1) at 30\% probability displacement.
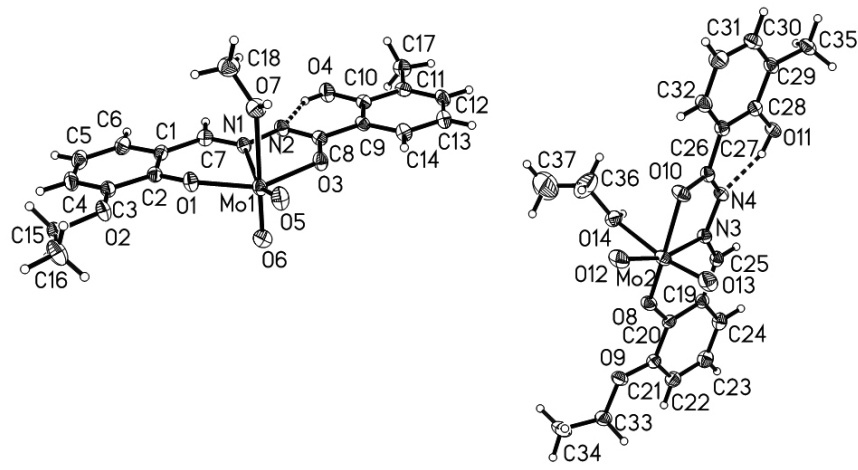

Figure 2 Molecular structure of (2) at 30\% probability displacement.

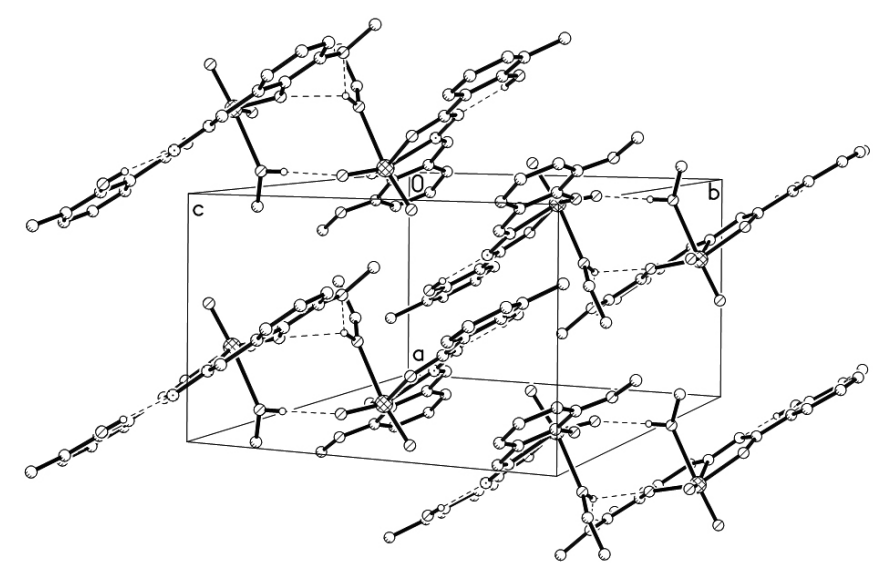

Figure 3 The $\mathrm{O}-\mathrm{H} \cdots \mathrm{N}$ hydrogen bonds linked dimeric structure of (1).

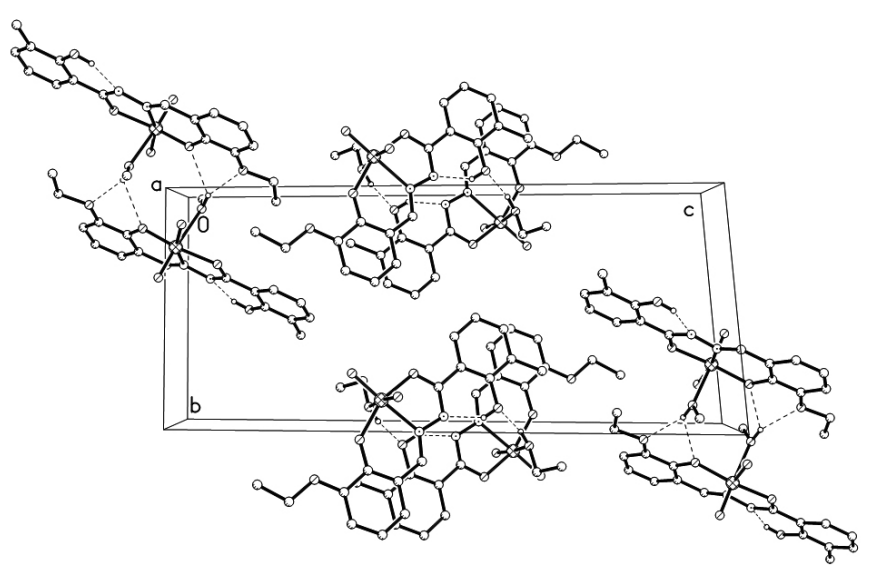

Figure 4 The $\mathrm{O}-\mathrm{H} \cdots \mathrm{N}$ hydrogen bonds linked dimeric structure of (2). 
Table 2 Selected bond lengths $(\AA \hat{)})$ and angles $\left(^{\circ}\right)$ for the complexes

\begin{tabular}{|c|c|c|c|}
\hline (1) & & & \\
\hline \multicolumn{4}{|l|}{ Bond lengths } \\
\hline Mo1-O1 & $1.919(3)$ & Mo1-O3 & $2.011(3)$ \\
\hline Mo1-O5 & $1.707(3)$ & Mo1-O6 & $1.686(3)$ \\
\hline Mo1-N1 & $2.237(3)$ & Mo1-O4 & $2.343(3)$ \\
\hline Mo2-O11 & $1.687(3)$ & Mo2-O13 & $1.695(3)$ \\
\hline Mo2-O7 & $1.939(3)$ & Mo2-O10 & $1.999(3)$ \\
\hline Mo2-N3 & $2.258(3)$ & Mo2-O12 & $2.330(3)$ \\
\hline \multicolumn{4}{|l|}{ Bond angles } \\
\hline O6-Mo1-O5 & $105.8(1)$ & O6-Mo1-O1 & $99.0(1)$ \\
\hline O5-Mo1-O1 & $104.8(1)$ & O6-Mo1-O3 & $98.4(1)$ \\
\hline O5-Mo1-O3 & $95.9(1)$ & O1-Mo1-O3 & 148.2(1) \\
\hline O6-Mo1-N1 & $91.7(1)$ & O5-Mo1-N1 & 160.1(1) \\
\hline O1-Mo1-N1 & 81.1(1) & O3-Mo1-N1 & $71.8(1)$ \\
\hline O6-Mo1-O4 & $170.5(1)$ & O5-Mo1-O4 & $83.6(1)$ \\
\hline O1-Mo1-O4 & $80.0(1)$ & O3-Mo1-O4 & $78.6(1)$ \\
\hline N1-Mo1-O4 & $78.8(1)$ & O11-Mo2-O13 & 105.3(1) \\
\hline O11-Mo2-O7 & $99.6(1)$ & O13-Mo2-O7 & $103.5(1)$ \\
\hline O11-Mo2-O10 & $99.3(1)$ & O13-Mo2-O10 & $97.0(1)$ \\
\hline O7-Mo2-O10 & 147.3(1) & O11-Mo2-N3 & $91.9(1)$ \\
\hline O13-Mo2-N3 & $161.0(1)$ & O7-Mo2-N3 & $81.1(1)$ \\
\hline O10-Mo2-N3 & $71.8(1)$ & O11-Mo2-O12 & $168.2(1)$ \\
\hline O13-Mo2-O12 & $86.5(1)$ & O7-Mo2-O12 & $77.8(1)$ \\
\hline O10-Mo2-O12 & $78.4(1)$ & N3-Mo2-O12 & $76.4(1)$ \\
\hline \multicolumn{4}{|l|}{$(2)$} \\
\hline \multicolumn{4}{|l|}{ Bond lengths } \\
\hline Mo1-O1 & $1.943(2)$ & Mo1-O3 & $2.017(2)$ \\
\hline Mo1-O5 & $1.693(3)$ & Mo1-O6 & $1.678(3)$ \\
\hline Mo1-N1 & $2.238(3)$ & Mo1-O7 & $2.363(3)$ \\
\hline Mo2-O8 & $1.918(2)$ & Mo2-O10 & $2.028(3)$ \\
\hline Mo2-O12 & $1.692(3)$ & Mo2-O13 & $1.690(3)$ \\
\hline Mo2-N3 & $2.237(3)$ & Mo2-O14 & $2.342(3)$ \\
\hline \multicolumn{4}{|l|}{ Bond angles } \\
\hline O6-Mo1-O5 & $105.8(1)$ & O6-Mo1-O1 & $99.7(1)$ \\
\hline O5-Mo1-O1 & $103.7(1)$ & O6-Mo1-O3 & $96.9(1)$ \\
\hline O5-Mo1-O3 & $96.2(1)$ & O1-Mo1-O3 & 149.3(1) \\
\hline O6-Mo1-N1 & $95.7(1)$ & O5-Mo1-N1 & $156.6(1)$ \\
\hline O1-Mo1-N1 & $81.1(1)$ & O3-Mo1-N1 & $71.7(1)$ \\
\hline O6-Mo1-O7 & $172.7(1)$ & O5-Mo1-O7 & $80.9(1)$ \\
\hline O1-Mo1-O7 & $81.1(1)$ & O3-Mo1-O7 & $79.4(1)$ \\
\hline N1-Mo1-O7 & $77.2(1)$ & O13-Mo2-O12 & 106.2(1) \\
\hline O13-Mo2-O8 & $100.9(1)$ & O12-Mo2-O8 & $103.7(1)$ \\
\hline O13-Mo2-O10 & $95.7(1)$ & O12-Mo2-O10 & $96.4(1)$ \\
\hline O8-Mo2-O10 & 149.1(1) & O13-Mo2-N3 & $92.6(1)$ \\
\hline O12-Mo2-N3 & $159.1(1)$ & O8-Mo2-N3 & $81.2(1)$ \\
\hline O10-Mo2-N3 & $72.1(1)$ & O13-Mo2-O14 & 169.1(1) \\
\hline O12-Mo2-O14 & $83.1(1)$ & O8-Mo2-O14 & $82.0(1)$ \\
\hline O10-Mo2-O14 & $77.2(1)$ & N3-Mo2-O14 & $77.4(1)$ \\
\hline
\end{tabular}

\section{CONCLUSION}

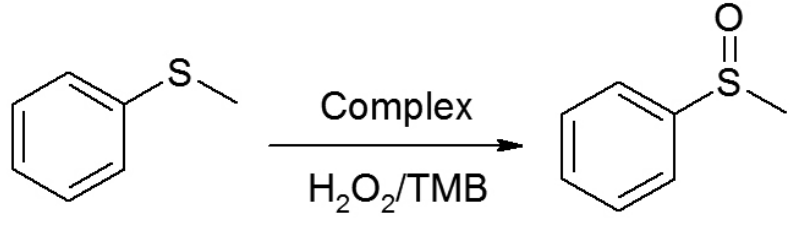

Scheme 3: The sulfoxidation process.
In summary, two new dioxomolybdenum(VI) complexes with similar benzohydrazone ligands have been synthesized and characterized. The benzohydrazone ligands coordinate to the Mo atom through enolic forms by using the phenolate $\mathrm{O}$, imine $\mathrm{N}$ and enolic $\mathrm{O}$ atoms. Both complexes have effective catalytic properties for the sulfoxidation of sulfides.

Supplementary material

CCDC-891854 (1) and 891855 (2) contain the supplementary crystallographic data for this paper. The data can be obtained free of charge at 
J. Chil. Chem. Soc., 58, № 1 (2013)

http://www.ccdc.cam.ac.uk/const/retrieving.html or from the Cambridge Crystallographic Data Centre (CCDC), 12 Union Road, Cambridge CB2 1EZ, UK; fax: +44(0)1223-336033 or e-mail: deposit@ccdc.cam.ac.uk.

Table 3 Hydrogen geometries for the complexes.

\begin{tabular}{|l|l|l|l|l|}
\hline$D-\mathrm{H} \cdots A$ & $d(D-\mathrm{H})(\AA)$ & $d(\mathrm{H} \cdots A)(\AA)$ & $d(D \cdots A)(\AA)$ & Angle $(D-\mathrm{H} \cdots A)\left({ }^{\circ}\right)$ \\
\hline$(\mathbf{1})$ & & & & \\
\hline $\mathrm{O} 9-\mathrm{H} 9 \cdots \mathrm{N} 4$ & 0.82 & 1.92 & $2.643(4)$ & 146 \\
\hline $\mathrm{O} 14-\mathrm{H} 14 \cdots \mathrm{N} 2$ & 0.82 & 1.88 & $2.610(4)$ & 147 \\
\hline $\mathrm{O} 12-\mathrm{H} 12 \cdots \mathrm{O} 5^{\text {i }}$ & $0.85(1)$ & $1.99(3)$ & $2.759(4)$ & $151(5)$ \\
\hline $\mathrm{O} 4-\mathrm{H} 4 \cdots 8^{\text {ii }}$ & $0.85(1)$ & $2.14(3)$ & $2.888(4)$ & $147(5)$ \\
\hline $\mathrm{O} 4-\mathrm{H} 4 \cdots \mathrm{O} 7^{\text {ii }}$ & $0.85(1)$ & $2.51(3)$ & $3.231(4)$ & $145(5)$ \\
\hline$(2)$ & & & & \\
\hline $\mathrm{O} 4-\mathrm{H} 4 \cdots \mathrm{N} 2$ & 0.82 & 1.89 & $2.607(4)$ & 145 \\
\hline $\mathrm{O} 11-\mathrm{H} 11 \cdots \mathrm{N} 4$ & 0.82 & 1.86 & $2.583(4)$ & 147 \\
\hline $\mathrm{O} 14-\mathrm{H} 14 \cdots \mathrm{O} 11^{\text {iii }}$ & $0.85(1)$ & $1.96(2)$ & $2.785(3)$ & $163(5)$ \\
\hline $\mathrm{O} 7-\mathrm{H} 7 \cdots \mathrm{O} 1^{\text {iv }}$ & $0.85(1)$ & $2.51(4)$ & $3.174(4)$ & $137(4)$ \\
\hline $\mathrm{O} 7-\mathrm{H} 7 \cdots \mathrm{O} 2^{\text {iv }}$ & $0.85(1)$ & $2.19(2)$ & $2.970(4)$ & $154(5)$ \\
\hline
\end{tabular}

Symmetry codes: i) $x,-1+y, z$; ii) $x, 1+y, z$; iii) $1-x, 2-y, 1-z$; iv) $2-x,-y,-z$

\section{ACKNOWLEDGMENTS}

This research was supported by the National Sciences Foundation of China (No. 20676057 and 20877036) and Top-class foundation of Pingdingshan University (No. 2008010).

\section{REFERENCES}

1. C.A. Gamelas, A.C. Gomes, S.M. Bruno, F.A.A. Paz, A.A. Valente, M. Pillinger, C.C. Romao, I.S. Goncalves, Dalton Trans. 41, 3474, (2012).

2. L.S. Feng, J.S. Maass, R.L. Luck, Inorg. Chim. Acta 373, 85, (2011).

3. M. Bagherzadeh, M. Amini, A. Ellern, L.K. Woo, Inorg. Chem. Commun. 15, 52, (2012).

4. S. Rayati, N. Rafiee, A. Wojtczak, Inorg. Chim. Acta 386, 27, (2012).

5. B.I. Ceylan, Y.D. Kurt, B. Ulkuseven, J. Coord. Chem. 62, 757, (2009).

6. M.N. Sokolov, M.A. Mikhailov, P.A. Abramov, V.P. Fedin, J. Struct Chem. 53, 197, (2012).

7. S.-P. Gao, J. Coord. Chem. 64, 2869, (2011).

8. V. Vrdoljak, B. Prugovecki, D. Matkovic-Calogovic, J. Pisk, R. Dreos, P. Siega, Cryst. Growth Des. 11, 1244, (2011).
9. J. Chakraborty, S. Thakurta, G. Pilet, D. Luneau, S. Mitra, Polyhedron 28, 819, (2009)

10. H.H. Monfared, J. Sanchiz, Z. Kalantari, C. Janiak, Inorg. Chim. Acta 362, 3791, (2009).

11. M. Mancka, W. Plass, Inorg. Chem. Commun. 10, 677, (2007).

12. S.N. Rao, N. Kathale, N.N. Rao, K.N. Munshi, Inorg. Chim. Acta 360, 4010, (2007).

13. R. Dinda, S. Ghosh, L.R. Falvello, M. Tomás, T.C.W. Mak, Polyhedron 25, 2375, (2006).

14. SMART and SAINT, Area Detector Control and Integration Software, Madison (WI, USA): Bruker Analytical X-ray Instruments Inc., (1997).

15. Sheldrick, G.M., SADABS, Program for Empirical Absorption Correction of Area Detector Data. Göttingen (Germany): University of Göttingen, (1997).

16. A.C.T. North, D.C. Phillips, F.S. Mathews, Acta Crystallogr. A24, 351, (1968).

17. G.M. Sheldrick, SHELXL-97, Program for the Refinement of Crystal Structures, Göttingen (Germany): University of Göttingen, (1997).

18. S.N. Rao, K.N. Munshi, N.N. Rao, M.M. Bhadbhade, E. Suresh, Polyhedron 18, 2491, (1999).

19. W.-X. Xu, W.-H. Li, Synth. React. Inorg. Met.-Org. Nano-Met. Chem. 42, 160, (2012). 